"This is the peer reviewed version of the following article: Franko M, Sedlaček M, Podgornik B, Nagode M. Validation of linear damage rules using random loading. Int J Damage Mechanics. 2017; 26:463-479., which has been published in final form at DOI: $10.1177 / 1056789515605881$. This article may be used for non-commercial purposes for Use of Self-Archived Versions."

\title{
Validation of linear damage rules using random loading
}

Mitja Franko $^{1}$, Marko Sedlaček ${ }^{2}$, Bojan Podgornik $^{2}$ and Marko Nagode ${ }^{1}$

\begin{abstract}
Fatigue damage is a parameter which plays an important role in lifetime and reliability predictions of randomly loaded structures. In this paper, four different forms of the Miner linear accumulation damage rule are examined. They are used to compare observed experimental damage and the results of numerical simulations for both uniaxial and multiaxial fatigue. First, critical fatigue damage values for all forms of the Miner accumulation damage rule are calculated for uniaxial cases. Based on the results presented in this paper, it has been established that for high strength materials the critical damage value is around 0.3. These results are then applied to the multiaxial cases. The multiaxiality is taken into account using either the signed von Mises or critical plane method. Finally, the fatigue fracture surface has been calculated and compared to the experimental pattern of fatigue fracture. The results show that the fatigue fracture surface determined by the numerical simulation is comparable to the fatigue fracture observed experimentally.
\end{abstract}

\section{Keywords}

Damage, fatigue, multiaxial, critical plane, signed von Mises

${ }^{\mathrm{I}}$ Faculty of Mechanical Engineering,

University of Ljubljana, Slovenia

${ }^{2}$ Metallic Materials and Technology Department, Institute of Metals and Technology, Slovenia

\section{Corresponding author:}

Mitja Franko, Faculty of Mechanical Engineering, University of Ljubljana, Aškerčeva 6, 1000

Ljubljana, Slovenia.

Email: mitja.franko@fs.uni-lj.si 


\section{Introduction}

Fatigue damage calculations of structures subjected to random multiaxial loading is a complex issue. It requires knowledge of the loading history, stress-life curves, multiaxial fatigue criterion and the damage accumulation rule. ${ }^{1,2}$ The calculation can be based either on experimental data or on the results of numerical simulations.

Numerical simulations are usually based on the finite element (FE) method and provide detailed information about the stress-strain response of the structure. The use of FE method for damage calculation is suitable. ${ }^{1,2}$ However, it is not practical due to the computational effort required for relatively long load histories. In the field of high cycle fatigue, the computational effort can be reduced using the superposition of loads, where for each load direction the analysis with unit force is carried out. ${ }^{1,2,3,4}$ Once the results of numerical simulations are known, the appropriate multiaxial fatigue criterion can be chosen. There are several multiaxial criteria in the literature. ${ }^{2,3,5,6,7}$ Here only those approaches that calculate equivalent stress at each node of the FE model and the critical plane approach, which considers the most critical plane in each node for fatigue damage estimation, will be used.

The stress-life curve is obtained from experimental fatigue tests at different stress levels, usually for fully reversed loading (stress ratio $R=-1) .{ }^{8}$ However, these tests can also be carried out at other stress ratios, for example at stress ratio $R=0$. High cycle fatigue tests are usually run until failure or until a very high number of cycles if failure does not occur, typically to $10^{7}$ cycles for steels. ${ }^{8}$ For high-strength steel, which is used here, it has been established that fatigue failure for fully reversed loading occurs before $10^{6}$ cycles, or after $10^{8}$ cycles. $^{9}$

Once the stress history at each node of the FE model and stress-life curves are known, the fatigue damage can be calculated using damage accumulation rules. The simplest and most widely used is the linear damage accumulation rule, often referred to as the Miner rule. This rule often leads to non-conservative life predictions, because it does not take into account the effect of load sequence on the accumulation of damage. ${ }^{10,11,12,13,14}$ Therefore, many different fatigue damage theories have been proposed to improve the life prediction. A comprehensive review of damage accumulation rules can be found elsewhere. ${ }^{15}$

If the Miner damage rule is used, it is usually assumed that failure occurs when the accumulated damage reaches unity. ${ }^{16}$ However, experimental results indicate that the accumulated damage at failure can be greater than one for a low-to-high loading sequence and less than one for a high-to-low loading sequence. ${ }^{12,15}$ For random loading sequences, the accumulated damage at failure is 0.3 for unwelded steel structures and 0.5 for welded steel structures. ${ }^{17}$ It should be noted that these values do not include a safety factor.

The purpose of this paper is to verify the correlation between calculated damage using the experimental test results and the results of numerical simulations for cases of uniaxial and multiaxial fatigue. First, the theoretical background of stress cycles, stress-life curves and different forms of the Miner linear damage accumulation rules are presented. The experimental data is followed by the numerical simulation model. Finally two multiaxial fatigue criteria are given. 


\section{Theoretical background}

The rainflow counting method ${ }^{2,8}$ is frequently used to extract load cycles from a stress history. The extracted stress cycles are described by cycle amplitude $S_{\mathrm{a}}$ and cycle mean value $S_{\mathrm{m}}$. Because the mean stress has a substantial influence on fatigue life, ${ }^{10,18}$ and thus on fatigue damage, it has to be accounted for using one of several mean stress correction methods for metals. ${ }^{19,20}$ Here the Goodman mean stress correction method ${ }^{2,19,20}$ is used (equation (1)).

$$
S_{\mathrm{ae}}=S_{\mathrm{a}}+M \cdot S_{\mathrm{m}}
$$

$S_{\text {ae }}$ represents the equivalent cycle stress amplitude at stress ratio $R=-1$ and $M$ is the slope of a line, which is given by ${ }^{21}$

$$
M=\frac{S_{\mathrm{a}, \mathrm{SR} 1}}{S_{\mathrm{a}, \mathrm{SR} 2}}-1,
$$

where $S_{\mathrm{a}, \mathrm{SR} 1}$ and $S_{\mathrm{a}, \mathrm{SR} 2}$ are the stress amplitudes at stress ratios $R=-1$ and $R=0$, respectively.

The stress-life curves are usually given in the form of Wöhler curves for constant amplitude loading. ${ }^{22}$ They are given as

$$
\frac{N_{1}}{N_{2}}=\left(\frac{S_{\mathrm{a} 1}}{S_{\mathrm{a} 2}}\right)^{-k},
$$

where $S_{\mathrm{a} 1}$ and $S_{\mathrm{a} 2}$ are cycle stress amplitudes, $N_{1}$ and $N_{2}$ are the corresponding numbers of cycles to failure and $k$ is the exponent of the Wöhler curve. Equation (3) can be linearised as 23,24

$$
\log N_{i}=A+B \cdot \log S_{\mathrm{a} i}
$$

where the intercept $A=\log N_{2}+k \cdot \log S_{\text {a2 }}$ and slope $B=-k$. The intercept and slope can be estimated using the linear least squares method. ${ }^{25}$

For $n_{\mathrm{SR} 1}$ test results with a stress ratio $R=-1$ and $n_{\mathrm{SR} 2}$ test results with a stress ratio $R=0$, two linear models are given with the same slope

$$
\begin{array}{ll}
\log N_{\mathrm{SR} 1 i}=A_{\mathrm{SR} 1}+B \cdot \log S_{\mathrm{a}, \mathrm{SR} 1 i} ; & i=1, \ldots, n_{\mathrm{SR} 1} \\
\log N_{\mathrm{SR} 2 j}=A_{\mathrm{SR} 2}+B \cdot \log S_{\mathrm{a}, \mathrm{SR} 2 j} ; & j=1, \ldots, n_{\mathrm{SR} 2 .}
\end{array}
$$

The slope is evaluated as $^{26}$

$$
B=\frac{\sum_{i=1}^{n_{S R 1}} x_{S R 1 i} y_{S R 1 i}+\sum_{j=1}^{n_{S R 2}} x_{S R 2 j} y_{S R 2 j}-\frac{1}{n_{S R 1}} \sum_{i=1}^{n_{S R 1}} x_{S R 1 i} \sum_{i=1}^{n_{S R 1}} y_{S R 1 i}-\frac{1}{n_{S R 2}} \sum_{j=1}^{n_{S R 2}} x_{S R 2 j} \sum_{j=1}^{n_{S R 2}} y_{S R 2 j}}{\sum_{i=1}^{n_{S R 1}} x_{S R 1 i}^{2}+\sum_{j=1}^{n_{S R 2}} x_{S R 2 j}^{2}-\frac{1}{n_{S R 1}}\left(\sum_{i=1}^{n_{S R 1}} x_{S R 1 i}\right)^{2}-\frac{1}{n_{S R 2}}\left(\sum_{j=1}^{n_{S R 2}} x_{S R 2 j}\right)^{2}}
$$

and the intercepts as

$$
A_{\mathrm{SR} 1}=\frac{1}{n_{\mathrm{SR} 1}} \sum_{i=1}^{n_{\mathrm{SR} 1}} y_{\mathrm{SR} 1 i}-B \frac{1}{n_{\mathrm{SR} 1}} \sum_{i=1}^{n_{\mathrm{SR} 1}} x_{\mathrm{SR} 1 i}
$$




$$
A_{\mathrm{SR} 2}=\frac{1}{n_{\mathrm{SR} 2}} \sum_{j=1}^{n_{\mathrm{SR} 2}} y_{\mathrm{SR} 2 j}-B \frac{1}{n_{\mathrm{SR} 2}} \sum_{j=1}^{n_{\mathrm{SR} 2}} x_{\mathrm{SR} 2 j} \text {, }
$$

where $x_{\mathrm{SR} 1 i}=\log S_{\mathrm{a}, \mathrm{SR} 1 i}, y_{\mathrm{SR} 1 i}=\log N_{\mathrm{SR} 1 i}, x_{\mathrm{SR} 2 j}=\log S_{\mathrm{a}, \mathrm{SR} 2 j}, y_{\mathrm{SR} 2 j}=\log N_{\mathrm{SR} 2 j} . N_{\mathrm{SR} 1}$ and $N_{\mathrm{SR} 2}$ are numbers of cycles to failure at stress ratios of $R=-1$ and $R=0$, respectively.

Once the stress cycles and the Wöhler curves are known, the fatigue damage value can be calculated. Due to its simplicity, the most widely used damage rule is the Miner linear damage accumulation rule. ${ }^{13,22}$ Different forms of the Miner linear damage accumulation rule are available. The critical fatigue damage value $D_{\mathrm{DR} l}$ for all forms of the rule usually ranges between 0 and $1,{ }^{17}$ where 0 means no damage has occurred and 1 represents failure.

$$
D_{\mathrm{DR} l}=\sum_{i=1}^{n} D_{\mathrm{DR} l, i} ; \quad l=1, \ldots, 4
$$

The index $l$ represents one of the four forms of the damage rule examined here. They are: ${ }^{21}$ a) the elementary Miner rule, b) the original Miner rule, c) the Haibach rule by considering the fictitious slope under the endurance limit and d) the consistent Miner rule by considering the sequence of stress cycles. Some of those damage rules need the information about the endurance limit of the material, which can be determined by the Probit method ${ }^{21}$ for $50 \%$ probability of failure.

a) The elementary Miner (EM) rule assumes that all stress cycles contribute to fatigue damage.

$$
D_{\mathrm{DR} 1, i}=\frac{S_{\mathrm{ae}, i}^{k}}{N_{\mathrm{E}} S_{\mathrm{E}}^{k}} ; \quad S_{\mathrm{ae}, i}>0
$$

b) The original Miner (OM) rule assumes that stress cycles smaller than the endurance limit do not contribute to fatigue damage.

$$
D_{\mathrm{DR} 2, i}=\left\{\begin{array}{cc}
\frac{S_{\mathrm{a}, i}^{k}}{N_{\mathrm{E}} S_{\mathrm{E}}^{k}} ; & S_{\mathrm{ae}, i} \geq S_{\mathrm{E}} \\
0 ; & S_{\mathrm{ae}, i}<S_{\mathrm{E}}
\end{array}\right.
$$

c) The Haibach $(\mathrm{H})$ rule assumes that stress cycles smaller than the endurance limit contribute to fatigue damage, however to a lesser extent than those stress cycles greater than the endurance limit. The Wöhler curve has a knee point at the endurance limit border. Beyond this point the Wöhler curve continues with a smaller slope $k+q$ and according to Gatts $^{21,27}$ the coefficient $q=k-1$. Hence the slope of the Wöhler curve under the endurance limit is $2 k-1$.

$$
D_{\mathrm{DR} 3, i}= \begin{cases}\frac{S_{\mathrm{ae}, i}^{k}}{N_{\mathrm{E}} S_{E}^{k}} ; & S_{\mathrm{ae}, i} \geq S_{\mathrm{E}} \\ \frac{S_{\mathrm{ae}, i}^{k+q}}{N_{\mathrm{E}} S_{E}^{k+q}} ; & S_{\mathrm{a} e, i}<S_{\mathrm{E}}\end{cases}
$$


d) The consistent Miner (CM) rule treats each stress cycle separately. According to Haibach $^{21}$ each stress cycle causing fatigue damage moves the Wöhler curve downward and to the left in proportion to the size of the damage caused. However, this movement does not change the slope of the Wöhler curve.

$$
D_{\mathrm{DR} 4, i}=\left\{\begin{array}{cl}
\frac{S_{\mathrm{a} e, i}^{k}}{N_{\mathrm{E}} S_{\mathrm{E}}^{k}} ; & S_{\mathrm{ae}, i} \geq S_{\mathrm{ED}, i} \\
0 ; & S_{\mathrm{ae}, i}<S_{\mathrm{ED}, i}
\end{array}\right.
$$

$S_{\mathrm{ED}, i}$ is the lowered endurance limit after each stress cycle that caused fatigue damage, and is calculated as

$$
S_{\mathrm{ED}, i}=S_{\mathrm{E}}\left(1-D_{\mathrm{DR} 4}^{*}\right)^{1 / q}
$$

where $D_{\mathrm{DR} 4}^{*}=\sum_{i=1}^{j} D_{\mathrm{DR} 4, i}$ represents the accumulated damage to the $j$-th of total $n$ stress cycles and $q$ is a freely selectable parameter between zero and infinity. If $q=0$, then the accumulated damage value equals the accumulated damage value of the elementary Miner rule, and if $q=\infty$, then the accumulated damage value equals the accumulated damage value of the original Miner rule (Figure 1). Here, the Gatts proposal $q=k-1$ will be used. It is apparent from equation (15) that the upper limit of $S_{\mathrm{ED}, i}$ is controlled by the initial value $S_{\mathrm{E}}$ and the lower limit by zero.

Knowledge of the changes in the number of cycles of knee point of the Wöhler curve $N_{\mathrm{ED}, i}$ is not required to calculate the fatigue damage. However, for comprehensive presentation the equations are given below.

The number of cycles of knee point of Wöhler curve at $S_{\mathrm{ED}, i}$ is calculated as

$$
N_{\mathrm{ED}, i}=N_{\mathrm{D}, i}\left(\frac{S_{\mathrm{ED}, i}}{S_{\mathrm{ae}, i}}\right)^{-k},
$$

where $N_{\mathrm{D}, i}$ is the number of cycles at $S_{\mathrm{ae}, i}$ of the shifted Wöhler curve

$$
N_{\mathrm{D}, i}=\left(1-D_{\mathrm{DR} 4}^{*}\right) N_{i}
$$

and $N_{i}$ is the number of cycles at $S_{\mathrm{ae}, i}$ of the original Wöhler curve. 

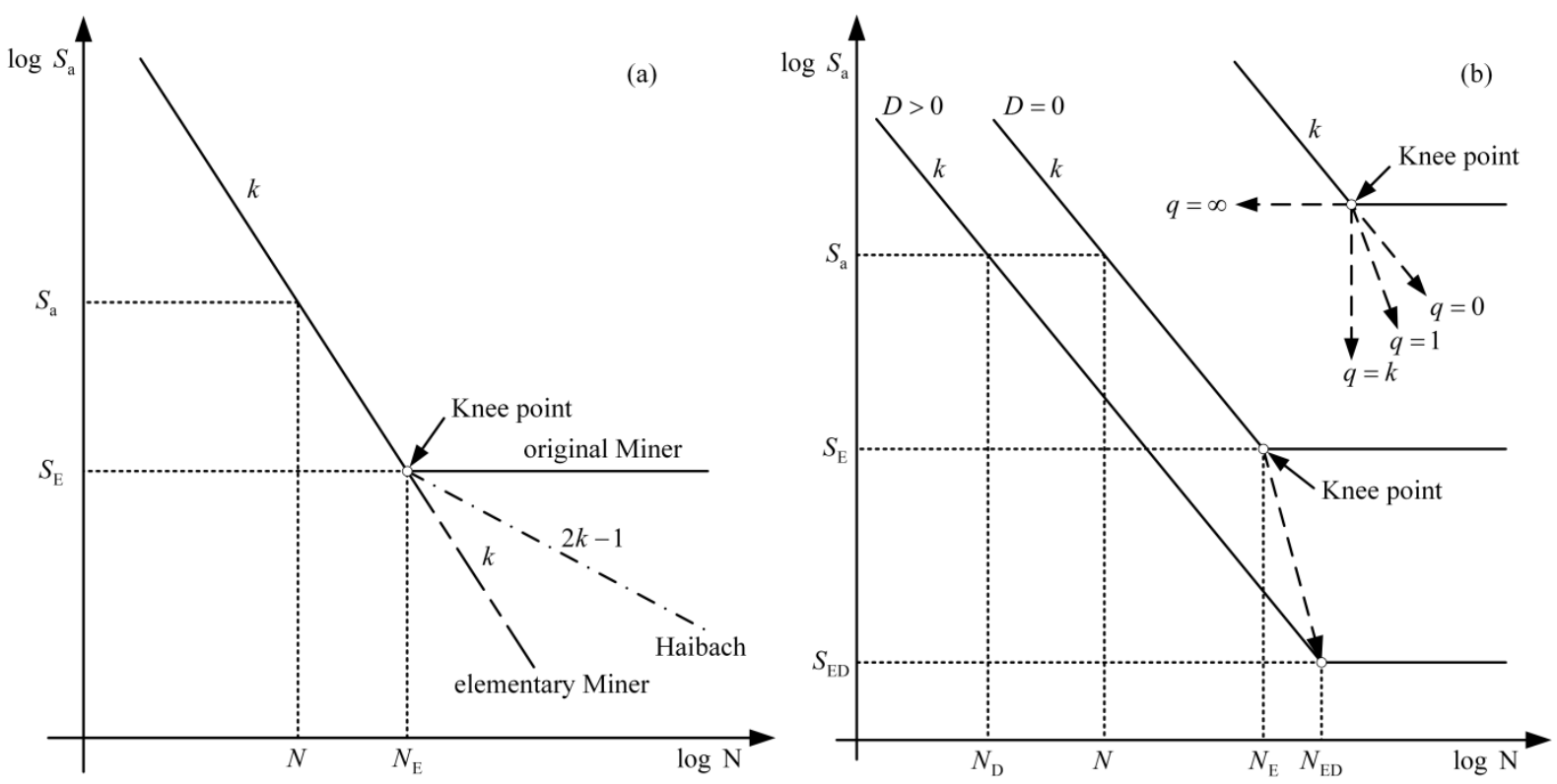

Figure 1. Linear damage rules: (a) original Miner, elementary Miner, Haibach rule and (b) consistent Miner rule. ${ }^{21}$

\section{Experimental procedure}

High cycle fatigue tests were carried out using an Instron 8802 servo hydraulic fatigue testing system, which was calibrated by an external accredited calibration laboratory and according to standard EN ISO 7500-1:2004. ${ }^{28}$ Polished hourglass-type test specimens with and without a hole (Figure 4) were made from commercial spring steel $51 \mathrm{CrV} 4$. The specimens were heat treated in the following manner. First, they were heated to $870{ }^{\circ} \mathrm{C}$, soaked in oil for $10 \mathrm{~min}$ and then quenched in nitrogen $\left(N_{2}\right)$ at a pressure of five bars to a temperature of $60{ }^{\circ} \mathrm{C}$. Finally, they were tempered at a temperature of $475{ }^{\circ} \mathrm{C}$ for one hour. Some of the static material properties are shown in Table 1.

Table 1. Static material properties of spring steel 51CrV4.

\begin{tabular}{lll}
\hline Material & & $51 \mathrm{CrV} 4$ \\
\hline Tensile strength & $S_{\mathrm{u}}[\mathrm{MPa}]$ & 1479 \\
Yield strength & $S_{\mathrm{y}}[\mathrm{MPa}]$ & 1413 \\
Elongation & $E l[\%]$ & 11.52 \\
Rockwell hardness & $\mathrm{HRC}$ & 43.1 \\
\hline
\end{tabular}

High cycle fatigue tests were carried out until failure or until $10^{6}$ number of cycles were achieved. All fatigue tests were carried out at room temperature $21 \pm 0.5^{\circ} \mathrm{C}$. In this study, five different loading methods were applied:

1) Sine wave loading of test specimens with no hole at $30 \mathrm{~Hz}$ and stress ratio $R=-1$ (Case 1). The samples were loaded at seven different levels. The amplitude of loading ranged from $780 \mathrm{MPa}$ to $540 \mathrm{MPa}$. 
2) Sine wave loading of test specimens with no hole at $30 \mathrm{~Hz}$ and stress ratio $R=0$ (Case 2). The samples were loaded at six different levels. The amplitude of loading ranged from $650 \mathrm{MPa}$ to $375 \mathrm{MPa}$.

3) Random loading of test specimens with no hole (Case 3). Random load history ranged from $-1000 \mathrm{MPa}$ to $1410 \mathrm{MPa}$.

4) Random loading of test specimens with no hole that withstood $10^{6}$ load cycles in Case 1) (Case 4). Random load history ranged from -1000 MPa to $1410 \mathrm{MPa}$.

5) Random loading of test specimens with a hole (Case 5). Random load history ranged from -1000 MPa to $1410 \mathrm{MPa}$.

Boundary between low-cycle fatigue (LCF) and high-cycle fatigue (HCF) is not exactly defined by a specific number of cycles. ${ }^{8}$ More relevant is that HCF is related to an elastic material behaviour on a macro scale. ${ }^{8}$ Here, the spring steel $51 \mathrm{CrV} 4$ with yield strength of $1413 \mathrm{MPa}$ is used. Experimental results for Cases 1 and 2 are presented in Table 2 and Figure 2. The loads are lower than the yield strength of the material, and therefore we can assume that the results are within HCF region.

Random load history in Figure 3(a) applied in Cases 3 to 5 is derived from the measured load history of a vehicle. The load cycles of the history are extracted by using the rainflow counting method and are arranged by cycle amplitude $S_{\text {a }}$ and cycle mean value $S_{\mathrm{m}}$ in Figure $3(b)$.

Table 2. Fatigue results for 51CrV4 steel.

\begin{tabular}{|c|c|c|c|c|c|c|c|}
\hline \multicolumn{8}{|c|}{ Stress ratio $R=-1$} \\
\hline$S_{a}[M P a]$ & 780 & 750 & 720 & 660 & 630 & 600 & 540 \\
\hline \multirow{6}{*}{$N$ [/] } & 18430 & 42100 & 46500 & 73500 & \multirow{6}{*}{$\begin{array}{l}>1 \cdot 10^{6} \\
>1 \cdot 10^{6} \\
>1 \cdot 10^{6}\end{array}$} & $>1 \cdot 10^{6}$ & $>1 \cdot 10^{6}$ \\
\hline & 23700 & 42400 & 48500 & 41200 & & \multirow{5}{*}{$\begin{array}{l}>1 \cdot 10^{6} \\
>1 \cdot 10^{6}\end{array}$} & \multirow{5}{*}{$\begin{array}{l}>1 \cdot 10^{6} \\
>1 \cdot 10^{6}\end{array}$} \\
\hline & 25000 & & 34200 & 44300 & & & \\
\hline & 26600 & & 42400 & 78700 & & & \\
\hline & 34800 & & & 92800 & & & \\
\hline & 42000 & & & $>1 \cdot 10^{6}$ & & & \\
\hline \multicolumn{8}{|c|}{ Stress ratio $R=0$} \\
\hline$S_{a}[M P a]$ & 650 & 600 & 562.5 & 525 & 507.5 & 375 & \\
\hline$N[/]$ & 17200 & 42500 & 83800 & 71000 & 113500 & $>2 \cdot 10^{6}$ & \\
\hline
\end{tabular}




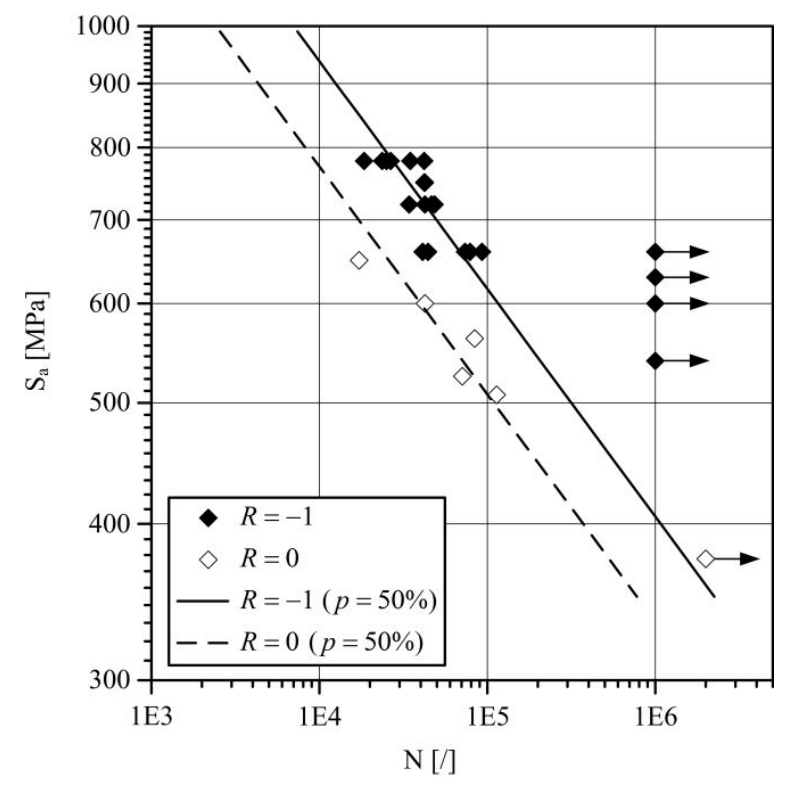

Figure 2. Wöhler curves for $51 \mathrm{CrV} 4$ steel.

Number of cycles $N$, e.g., ${ }^{8}$ shows less scatter at high stress amplitudes and large scatter at low stress amplitudes. The large scatter near the endurance limit is also the result of specimens that do not fail after a very high number of cycles (run-outs). ${ }^{8}$ Also, at low stress amplitudes, surface conditions (local surface inhomogeneities, small surface irregularities, slight surface damage) have a significant effect on $N$. As a result, more scatter is found at high endurances. ${ }^{8}$
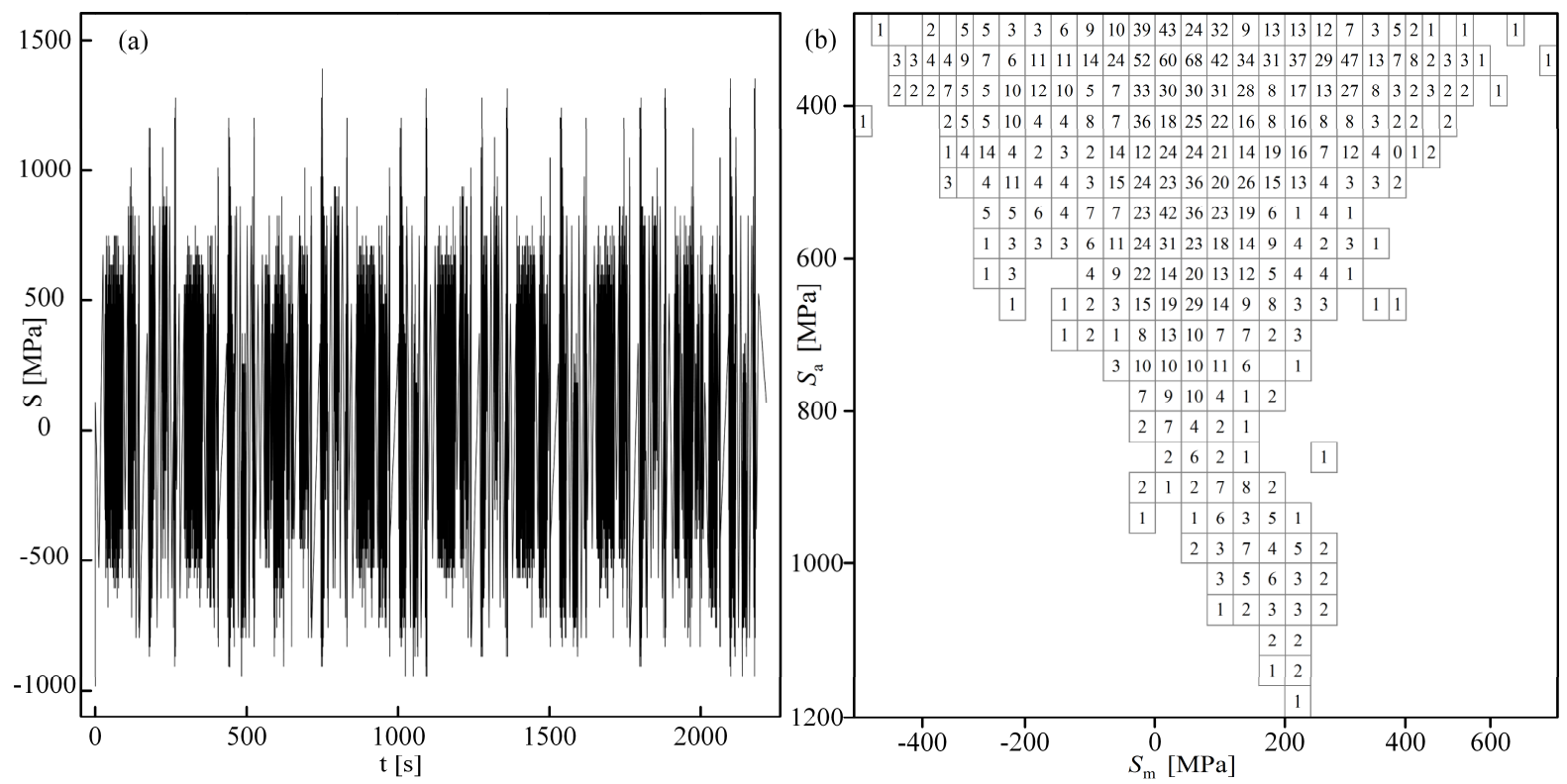

Figure 3. Load-time history (a) and rainflow matrix (b) for one load block. The numbers in rainflow matrix represent the number of cycles.

\section{Numerical simulations}


For high cycle fatigue tests circular cross-section test specimens with and without a hole were used (Figure 4). A $3 \mathrm{~mm}$ hole is positioned in the centre of one test specimen in order to achieve a complex stress state. With such a specimen a uniaxial test can be used to simulate the complex stress state around such a hole.

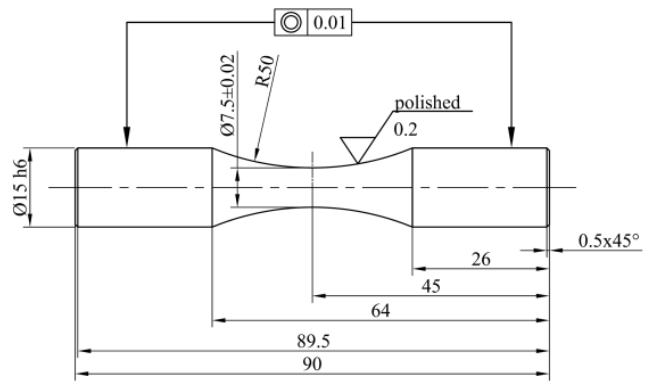

(a)

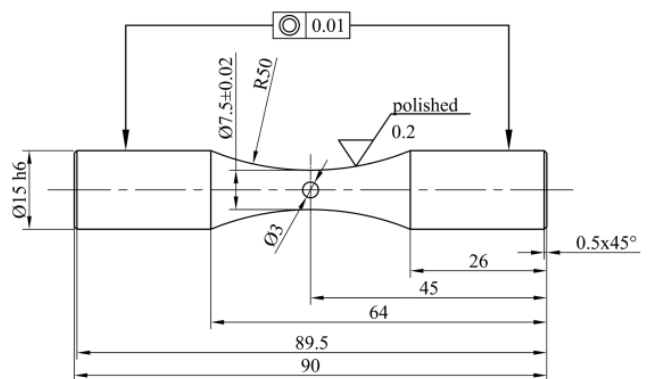

(b)

Figure 4. Axial force fatigue test specimen. (a) specimen with no hole and (b) specimen with hole.

Finite element (FE) analysis was performed using the finite element program Abaqus. Both FE models were meshed with quadratic hexahedral solid elements of type C3D20R with reduced integration. Figure 5 shows the FE mesh, boundary conditions and applied loads for models (a) with no hole and (b) with a hole, respectively. The FE mesh contains 12600 elements and 56441 nodes for the model with no hole, and 17569 elements and 78776 nodes for the model with a hole. At one end of the FE model, the three translational degrees of freedom are prevented whilst the load is applied at the other end.

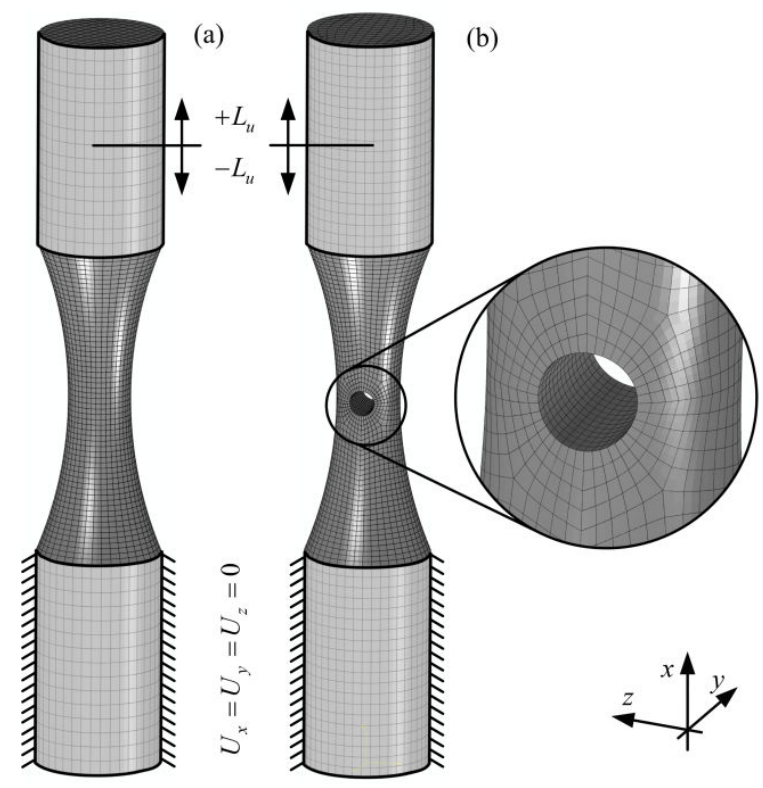


Figure 5. Finite element mesh, boundary conditions and applied loads for model (a) with no hole and (b) with hole.

Assuming small deformations, which in high cycle fatigue are ensured, superposition of loads can be applied. For each direction of loading the FE analysis with unit load $L_{u}$ is carried out. The result of such an analysis is a tensor of the stress influence factors $c_{k}$ for each direction of loading. This tensor is then combined with the load history $L_{k}(t)$ to calculate the stress histories $S(t)$ at each node of the FE model (equation (18)). ${ }^{1,2,4}$

$$
S(t)=\sum_{k=1}^{n} c_{k} L_{k}(t)
$$

The complex stress state is very common in engineering structures. The challenge is to transfer it into an equivalent uniaxial stress state. There are several methods available in the literature $2,3,5,6,7$, among which the critical plane, signed von Mises and energy methods are the most frequently used. The signed von Mises equivalent stress is recommended if the loading is proportional or nearly proportional. It gives conservative results by additionally taking into account the stresses in directions that do not contribute to the damage. ${ }^{2,3}$ If the loading is proportional or non-proportional, then the critical plane or energy methods are preferable.,10

In our case, the proportional loading is dominant causing the complex stress state around the hole. Hence, the signed von Mises equivalent stress (equation (19)) and the critical plane method (equation (20)) are used.

$$
\begin{aligned}
& S_{S V M}=S G N \cdot \frac{1}{\sqrt{2}}\left(\left(S_{x x}-S_{y y}\right)^{2}+\left(S_{x x}-S_{z z}\right)^{2}+\left(S_{y y}-S_{z z}\right)^{2}+6\left(\tau_{x y}^{2}+\tau_{x z}^{2}+\tau_{y z}^{2}\right)^{2}\right)^{1 / 2} \\
& S_{C P}=S_{x x} n_{x}^{2}+S_{y y} n_{y}^{2}+S_{z z} n_{z}^{2}+2 \tau_{x y} n_{x} n_{y}+2 \tau_{x z} n_{x} n_{z}+2 \tau_{y z} n_{y} n_{z},
\end{aligned}
$$

where $S G N$ is the same as the sign of the principal stress with the largest magnitude, ${ }^{2}$ $S_{x x}, S_{y y}, S_{z z}, \tau_{x y}, \tau_{x z}, \tau_{y z}$ are stress tensor components and $n_{x}, n_{y}, n_{z}$ are the directions of the normals.

The calculation of $S_{S V M}$ was carried out for the entire load history at each node. The same applies for $S_{C P}$, with the difference that at each node the load history has to be taken into account for each critical plane. In our case, the normal of the critical plane is $n=\left\{n_{x}, n_{y}, n_{z}\right\}=\{1,0,0\}$.

\section{Results and discussions}

\section{Results of finite element analysis}

Linear static FE analysis was performed using unit load and solid elements. The distribution of the von Mises stress for both FE models is presented in Figure 6. The maximum stresses occur across the minimum cross-section of the FE model with no hole and are homogeneous over the entire cross-section (Figure 6(a)). A complex stress state occurs around the hole of the FE model with a hole (Figure 6(b)). 


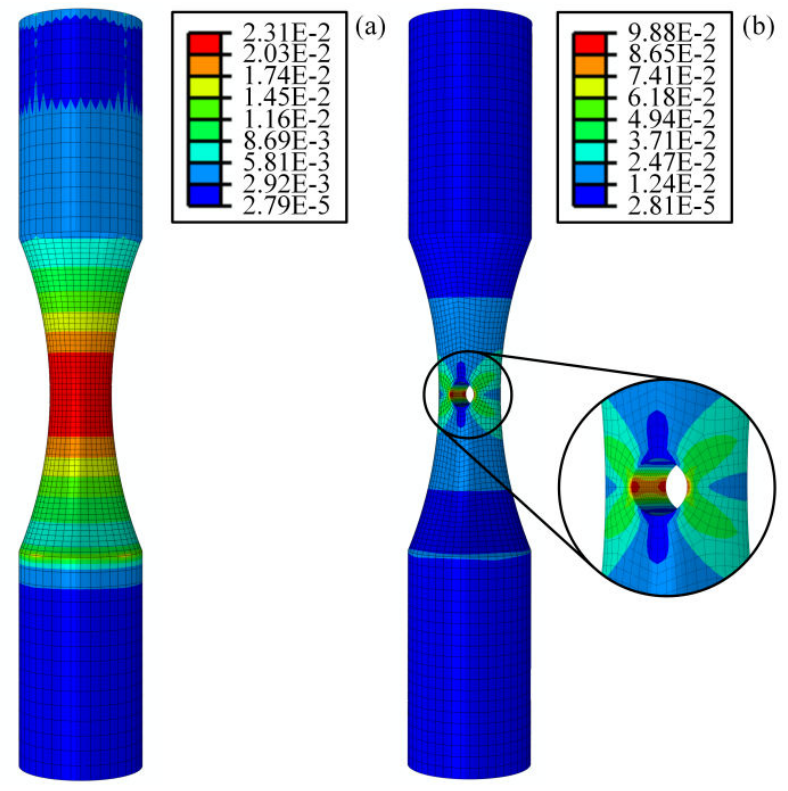

Figure 6. Von Mises equivalent stress for model (a) with no hole and (b) with hole.

Figures 7 and 8 show the complex stress state over the cross-section of the FE model with a hole for the von Mises equivalent stress and normal stress component $S_{x x}$, respectively. Elements and nodes of this cross-section are used in fatigue damage calculation.

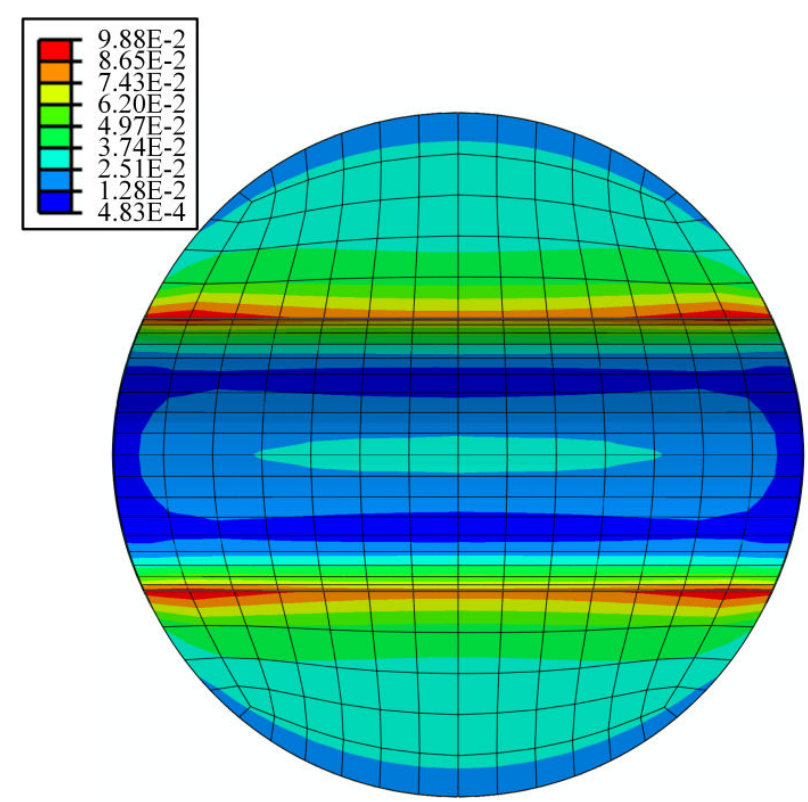

Figure 7. Distribution of the von Mises equivalent stress over the cross-section of the finite element model with a hole. 


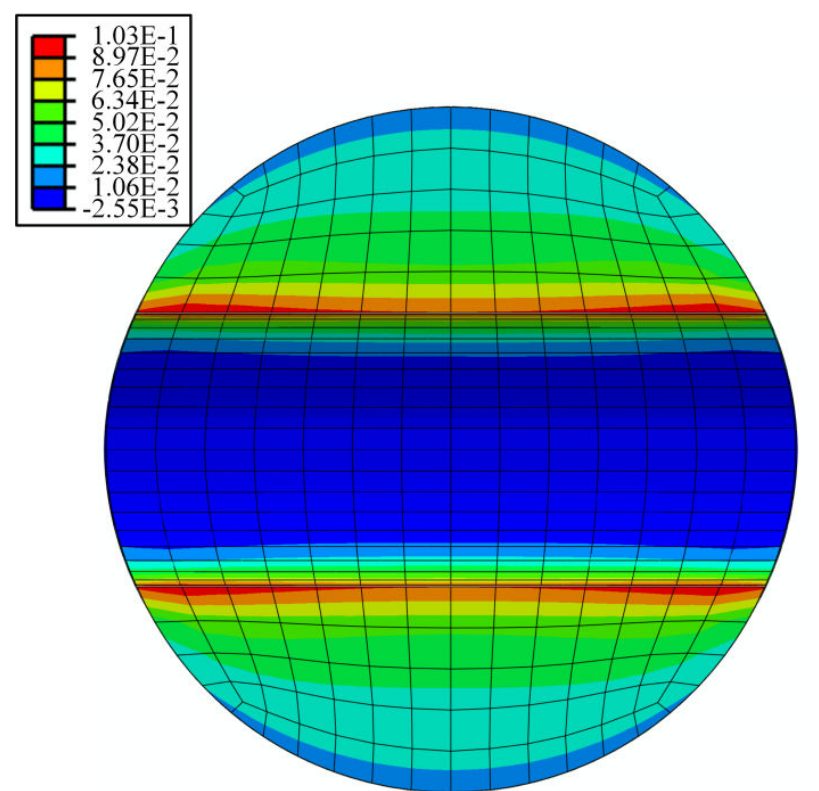

Figure 8. Distribution of the normal stress component $S_{x x}$ over the cross-section of the finite element model with a hole.

\section{Results of damage calculation}

The experimental and FE analysis results were used for damage calculations of specimens with and without a hole. Because the damage location of both specimens is known, the damage calculation was carried out only for those locations. The damage location occurs at the minimum cross-section.

The calculated damage values of specimens with no hole for two load cases, three different methods and all damage accumulation rules presented above are shown in Table 3 . In the first load case (Random), specimens were randomly loaded until failure, while in the second load case (Run out and random), they first withstood a million cycles of fully reversed loading, and then were randomly loaded in the same way as for first load case. Three different methods of calculating the stresses at the minimum cross-section were used. In the first method (Experimental) the stresses were calculated as $\sigma(t)=L_{k}(t) / A$, where $A$ represents the minimum cross-sectional area. In the second and third method (signed von Mises and critical plane), the stresses were calculated using equation (18), where stress influence factors were averaged over the whole cross-sectional area. The difference between the second and third method is only in the stress influence factors $c_{k}$. For each method, the damage for all damage accumulation rules was calculated twice, once taking into account mean stresses and once without (i.e. by applying the Goodman correction and no correction, respectively).

Based on the results shown in Table 3 it can be concluded that using the EM and OM rule always gives maximum and minimum damage, respectively. The calculated damage values using the $\mathrm{CM}$ rule are very close to the calculated damage values of $\mathrm{OM}$ rule, and the $\mathrm{H}$ rule always gives a damage value between those values obtained using the EM and CM rules. If the mean stresses are taken into account (using the Goodman correction) then the accumulated damage is on average $16 \%, 18 \%, 16 \%$ and $17 \%$ higher when using the EM, OM, $\mathrm{H}$ and $\mathrm{CM}$ rules, respectively. This clearly shows that the accumulated damage is underestimated if the mean stresses are ignored. The lowest accumulated damage value is obtained with the first method (Experimental) in both cases and for all damage rules. If the signed von Mises method 
with either Goodman or no mean stress correction is used then the accumulated damage is on average $12 \%, 14 \%, 15 \%$ and $16 \%$ higher for the EM, OM, $\mathrm{H}$ and $\mathrm{CM}$ rules, respectively. If the critical plane method is used then the accumulated damage is on average $18 \%, 24 \%$, $21 \%$ and $26 \%$ higher for the EM, OM, $\mathrm{H}$ and $\mathrm{CM}$ rules, respectively.

As mentioned previously, the difference between two load cases is only one million cycles. Results show that even when applying a million cycles some damage accumulates. The accumulated damage ranges between 0.02 and 0.04 for any combination of method, mean stress correction and damage accumulation rule.

Table 3. Calculated damage values of specimen with no hole for two load cases.

\begin{tabular}{|c|c|c|c|c|c|c|}
\hline \multirow[t]{2}{*}{ Load case } & \multirow[t]{2}{*}{ Method } & \multirow[t]{2}{*}{$\begin{array}{l}\text { Mean stress } \\
\text { correction }\end{array}$} & \multicolumn{4}{|c|}{ Damage rule } \\
\hline & & & $\begin{array}{c}\text { Elementary } \\
\text { Miner }\end{array}$ & $\begin{array}{l}\text { Original } \\
\text { Miner }\end{array}$ & Haibach & $\begin{array}{l}\text { Consistent } \\
\text { Miner }\end{array}$ \\
\hline \multirow{6}{*}{ 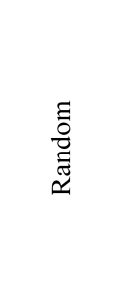 } & \multirow{2}{*}{ Experiment } & No correction & 0.24 & 0.19 & 0.22 & 0.20 \\
\hline & & Goodman correction & 0.28 & 0.23 & 0.25 & 0.23 \\
\hline & \multirow{2}{*}{$\begin{array}{c}\text { Signed } \\
\text { von Mises }\end{array}$} & No correction & 0.27 & 0.22 & 0.25 & 0.23 \\
\hline & & Goodman correction & 0.31 & 0.26 & 0.29 & 0.27 \\
\hline & \multirow{2}{*}{$\begin{array}{l}\text { Critical } \\
\text { plane }\end{array}$} & No correction & 0.28 & 0.24 & 0.26 & 0.25 \\
\hline & & Goodman correction & 0.33 & 0.28 & 0.31 & 0.29 \\
\hline \multirow{6}{*}{ 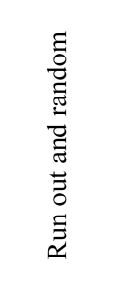 } & \multirow{2}{*}{ Experiment } & No correction & 0.21 & 0.17 & 0.19 & 0.17 \\
\hline & & Goodman correction & 0.24 & 0.20 & 0.22 & 0.20 \\
\hline & \multirow{2}{*}{$\begin{array}{c}\text { Signed } \\
\text { von Mises }\end{array}$} & No correction & 0.23 & 0.19 & 0.22 & 0.20 \\
\hline & & Goodman correction & 0.27 & 0.23 & 0.25 & 0.23 \\
\hline & \multirow{2}{*}{$\begin{array}{l}\text { Critical } \\
\text { plane }\end{array}$} & No correction & 0.25 & 0.21 & 0.23 & 0.21 \\
\hline & & Goodman correction & 0.29 & 0.24 & 0.27 & 0.25 \\
\hline
\end{tabular}

While the two load cases were applied to the specimen with no hole, only one load case (Random) was used for specimens with a hole. The complex stress state throughout the crosssection of the FE model with a hole for the von Mises equivalent stress and normal stress component $S_{x x}$ is shown in Figures 7 and 8, respectively. Results show that the distribution of accumulated damage depends on both the chosen multiaxial fatigue criterion and damage rule. A visual comparison of the accumulated damage distribution at the nodes for the EM damage rule using von Mises criterion and the critical plane method is given in Figures 9 and 10, respectively. As expected, the greatest damage occurs at the hole and decreases towards the outer diameter. 


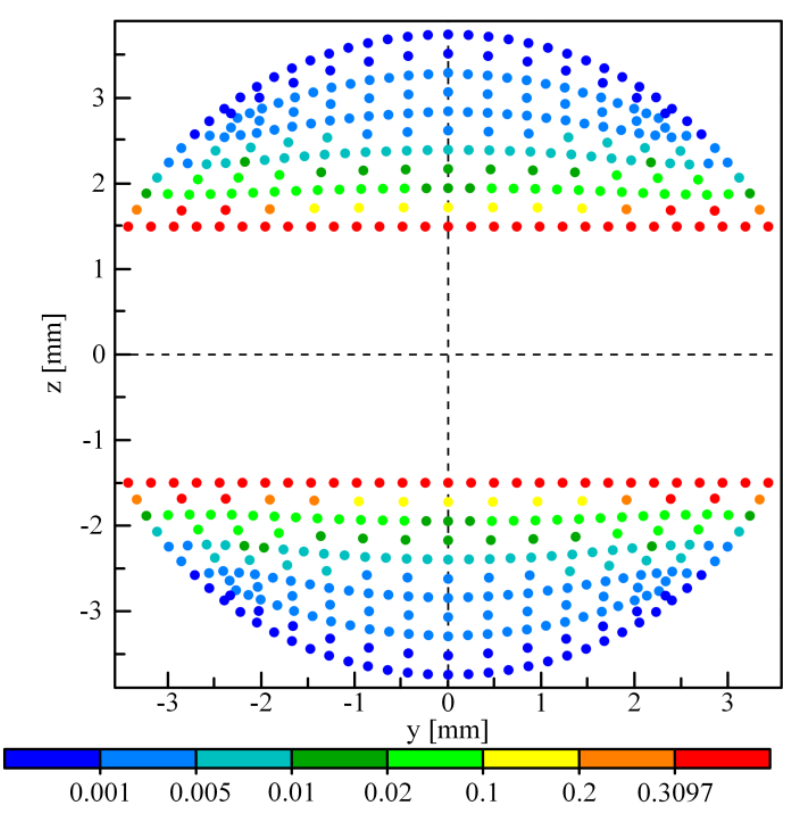

Figure 9. Accumulated damage distribution in nodes for the elementary Miner damage rule using signed von Mises criterion and Goodman mean stress correction method.

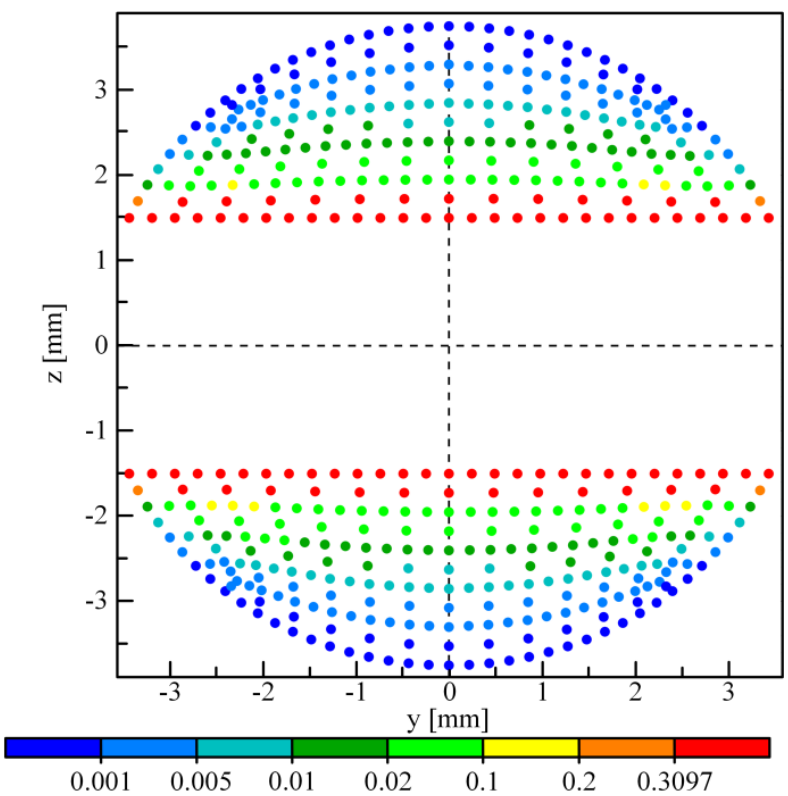

Figure 10. Accumulated damage distribution in nodes for the elementary Miner damage rule using the critical plane method and Goodman mean stress correction method.

Once, the accumulated damage in nodes is calculated the accumulated damage of each finite element can be calculated as the average of the accumulated damage in corresponding nodes (equation (21))

$$
D_{\mathrm{el}, i}=\left(\frac{1}{m} \sum_{j=1}^{m} D_{\mathrm{node}, j}\right)_{i} ; i=1, \ldots, n_{\mathrm{el}},
$$

where $D_{\mathrm{el}, i}$ is the accumulated damage of the $i$-th finite element, $D_{\text {node, } j}$ is the accumulated damage of the $j$-th node belonging to the $i$-th finite element, $m$ is the number of nodes of the 
$i$-th finite element and $n_{\mathrm{el}}$ is the number of finite elements across the selected cross-sectional area. Next, the finite elements are organised based on their accumulated damage in descending order from largest to smallest. The fatigue damage indicator can then be calculated using equation (22).

$$
D=\frac{\sum_{i=1}^{n_{\mathrm{el}}} D_{\mathrm{el}, i} \cdot V_{\mathrm{el}, i}}{V_{\max }-\sum_{i=1}^{n_{\mathrm{el}}} V_{\mathrm{el}, i}},
$$

where $D_{\mathrm{el}, i}$ is the accumulated damage of the $i$-th finite element, $V_{\max }$ is the gross volume of the finite elements across the selected cross-section area, $V_{\mathrm{el}, i}$ is the volume of the $i$-th finite element, $n_{\mathrm{el}}=136$ is the number of finite elements across the selected cross-section area and $D$ is the accumulated fatigue damage indicator. Initially we have virgin material for which D equals zero. If index $i$ increases the numerator increases and the denominator decreases. Therefore, D gradually increases from zero to the critical damage value in Table 3 . When the critical damage value is reached, specimen rupture is supposed to occur. The critical damage value is reached when $\mathrm{D}$ is slightly below 0.3 .

If the EM or $\mathrm{H}$ damage rule is used, then the critical damage value is reached and the correlation between the calculated and experimental fatigue fracture surfaces is adequate. As can be seen in Figure 11(a) and (c), the correlation is slightly better for the critical plane method. On the other hand, the critical damage value is not reached for OM and CM damage rules and the correlation between the calculated and experimental fatigue fracture surfaces in Figure 11(b) is not acceptable. If OM damage rule is used, then D is for 0.14 and 0.05 lower than the critical damage value for the signed von Mises and the critical plane method, respectively. If CM damage rule is used, then $\mathrm{D}$ is for 0.15 and 0.08 lower than the critical damage value for the signed von Mises and the critical plane method, respectively. It turns out that the critical plane method is favourable. 


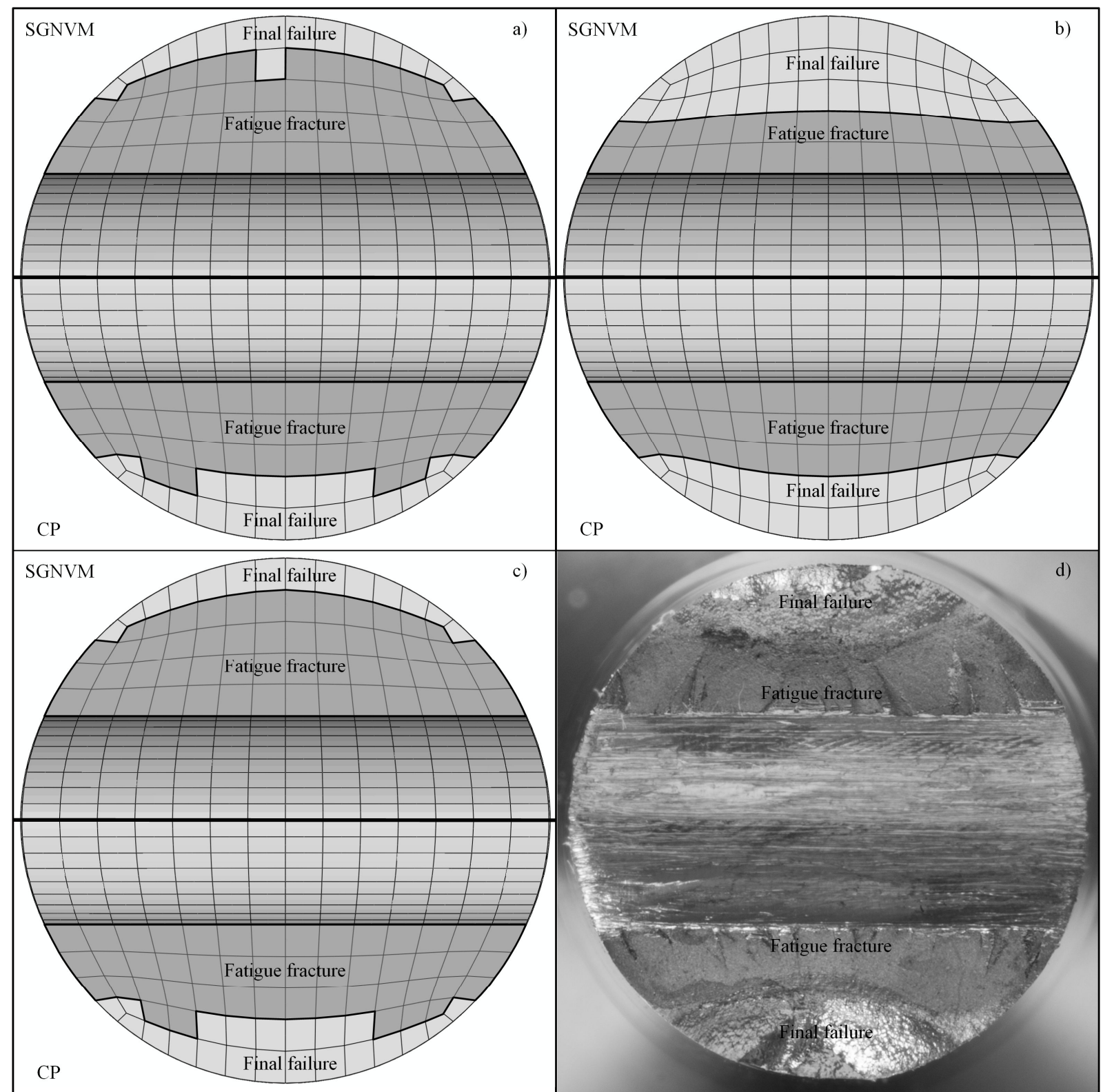

Figure 11. Fatigue fracture surface shown on finite element model for signed von Mises (SGNVM) and critical plane (CP) methods using a) the elementary Miner rule, b) the original Miner and consistent Miner rule, and c) the Haibach rule. (d) Fatigue fracture surface of a specimen with a hole.

\section{Conclusions}

Mechanical components fail when accumulated damage reaches a critical damage value. When Miner rules are used, it is usually assumed that the critical damage value is 1 . Based on the results presented in this paper, this has been shown not to be true for random loading. It has been established that for used material (high strength material) the critical damage value is slightly lower than 0.3 , which corresponds well to values in the literature. ${ }^{17}$ The values in literature ${ }^{17}$ relate to a wide range of steels. Here, a specific steel was used and therefore it is anticipated that the results will slightly deviate.

It has also been established that the mean stress value must be taken into account if the mechanical component is randomly loaded. The difference between ignoring and considering 
the mean stress value is approximately $17 \%$. Based on the results of multiaxial cases, the fatigue fracture surface determined by the numerical simulation is comparable to the experimental pattern of fatigue fracture, if $\mathrm{EM}$ or $\mathrm{H}$ damage rule is used and if a critical damage value of approximately 0.3 (Table 3 ) is considered.

\section{Acknowledgements}

The Department of Metallic Materials and Technologies, Institute of Metals and Technology Slovenia supported this research.

\section{References}

1. Kocabicak U, Firat M. A simple approach for multiaxial fatigue damage prediction based on FEM post-processing. Mater Des 2004; 25: 73-82.

2. LMS Falancs theory manual version 2.9. LMS Durability Technologies GmbH, 2002.

3. Rosa U, Nagode M, Fajdiga M. Strain-life approach in thermo-mechanical fatigue evaluation of complex structures. Fatigue Fract Engng Mater Struct 2007; 30: 808-822.

4. Rosa U. Durability prediction methods in the development of a product under thermomechanical fatigue. PhD Thesis, Faculty of Mechanical Engineering, University of Ljubljana, Slovenia, 2008.

5. Vu QH, Halm D, Nadot Y. High cycle fatigue of 1045 steel under complex loading: Mechanisms map and damage modelling. Int J Damage Mech 2014; 23(3): 377-410.

6. You B-R, Lee S-B. A critical review on multiaxial fatigue assessment of metals. Int J Fatigue 1996; 18(4): 235-244.

7. Papadopoulos IV, Davoli P, Gorla C, et al. A comparative study of multiaxial high-cycle fatigue criteria for metals. Int J Fatigue 1997; 19(3): 219-235.

8. Schijve J. Fatigue of structures and materials. 2nd ed. Boston: Springer, 2001

9. Bathais C. There is no infinite fatigue life in metallic materials. Fatigue Fract Engng Mater Struct 1999; 22: 559-565.

10. Stephens RI, Fatemi A, Stephens RR, et al. Metal fatigue in engineering. 2nd ed. New York: John Wiley \& Sons, 2001.

11. Lee Y-L, Pan J, Hathaway RB, et al. Fatigue testing and analysis: Theory and practice. Burlington: Elsevier Butterworth-Heinemann, 2005.

12. Zuo F-J, Huang H-Z, Zhu S-P, et al. Fatigue life prediction under variable amplitude loading using a non-linear damage accumulation model. Int J Damage Mech. Epub ahead of print 25 September 2014. DOI: 10.1177/1056789514553042.

13. Yuan R, Li H, Huang H-Z, et al. A nonlinear fatigue damage accumulation model considering strength degradation and its applications to fatigue reliability analysis. Int $\mathrm{J}$ Damage Mech. Epub ahead of print 17 July 2014. DOI: 10.1177/1056789514544228.

14. Lv Z, Huang H-Z, Zhu S-P, et al. A modified nonlinear fatigue damage accumulation model. Int J Damage Mech. Epub ahead of print 17 February 2014. DOI: $10.1177 / 1056789514524075$.

15. Fatemi A, Yang L. Cumulative fatigue damage and life prediction theories: a survey of the state of the art for homogeneous materials. Int J Fatigue 1998; 20(1): 9-34. 
16. Liu Y, Mahadevan S. Stochastic fatigue damage modelling under variable amplitude loading. Int J Fatigue 2007; 29: 1149-1161.

17. FKM Rihtlinie: Rechnerische festigkeitsnachweis für Maschinenbauteile aus Stahl, Eisenguss- und Aluminiumwerkstoffen. 6th ed. Frankfurt am Main: VDMA Verlag,2012.

18. Morrissey RJ, McDowell DL, Nicholas T. Frequency and stress ratio effects in high cycle fatigue of Ti-6Al-4V. Int J Fatigue 1999; 21: 679-685.

19. Ince A, Glinka G. A modification of Morrow and Smith-Watson-Topper mean stress correction models. Fatigue Fract Engng Mater Struct 2011; 34: 854-867.

20. Franko M, Nagode M. Probability density function of the equivalent stress amplitude using statistical transformation. Reliab Eng Syst Safe. Epub ahead of print 17 October 2014. DOI: 10.1016/j.ress.2014.10.012.

21. Haibach E. Betriebsfestigkeit: Verfahren und daten zur bauteilberechnung. 3rd ed. Berlin Hindelberg: Springer-Verlag New York, 2006.

22. Klemenc J, Fajdiga M. Description of statistical dependencies of parameters of random load states (dependency of random load parameters). Int J Fatigue 2000; 22: 357-367.

23. ASTM E739-10. Standard practise for statistical analysis of linear or linearized stress-Life $(\mathrm{S}-\mathrm{N})$ and strain-life $\left(\varepsilon_{-} \mathrm{N}\right)$ fatigue data.

24. Klemenc J, Fajdiga M. Estimating S-N curves and their scatter using a differential antstigmergy algorithm. Int J Fatigue 2012; 43: 90-97.

25. Rice JA. Mathematical Statistics and Data Analysis. 3rd ed. Belmont: Books/Cole, 2007.

26. Šeruga D, Hansenne E, Haesen V, et al. Durability prediction of EN 1.4512 exhaust mufflers under thermomechanical loading. Int J Mech Sci 2014; 84: 199-207.

27. Gatts RR. Application of a cumulative damage concept to fatigue. J Fluids Eng 1961; 83(4):529-534.

28. EN ISO 7500-1:2004. Metallic materials - Verification of static uniaxial testing machines - Part 1: Tension/compression testing machines - Verification and calibration of the force-measuring system. 